ALCHEMY Jurnal Penelitian Kimia

Laman resmi: https://jurnal.uns.ac.id/alchemy

\title{
Pengaruh Jumlah Katalis CaO terhadap Karakteristik Produk pada Sintesis Gliserol Karbonat
}

\author{
Gema Fitriyano", Syamsudin A. B., Adiwarna Adiwarna, Sarah Fauziah \\ Jurusan Teknik Kimia, Universitas Muhammadiyah Jakarta, Jakarta 10510, Indonesia \\ ${ }^{*}$ Corresponding author: gema.fitriyano@ftumj.ac.id \\ DOI: 10.20961/alchemy.16.2.38375.211-217
}

Received 24 December 2019, Accepted 29 June 2020, Published 01 September 2020

\begin{abstract}
Kata kunci:
ABSTRAK. Senyawa gliserol karbonat merupakan turunan gliserol yang saat ini masih berkembang $\mathrm{CaO}$ gliserol; gliserolisis; urea. diaplikasikan karena bahan baku yang lebih mudah didapatkan, penanganan lebih sederhana dan lebih murah dibandingkan proses sintesis lainnya. Penelitian ini bertujuan untuk melakukan karakterisasi terhadap produk hasil reaksi gliserolisis urea yang dioperasikan pada kondisi operasi suhu $140{ }^{\circ} \mathrm{C}$, tekanan $0,7 \mathrm{~atm}$ selama 4 jam dengan variasi jumlah katalis $\mathrm{CaO} 1,2,3,4$, dan $5 \%$ mol. Bahan hasil reaksi dianalisis gugus fungsinya menggunakan instrumen Fourier Transform Infra Red (FTIR) dan komposisi senyawanya menggunakan instrumen Gas Chromatography Mass Spectrophotometry (GC-MS). Analisis yang dilakukan terhadap produk menyimpulkan bahwa kondisi optimum diperoleh dari hasil reaksi gliserolsis urea dengan jumlah penggunaan katalis 5\% mol dengan menghasilkan nilai konversi $23 \%$.
\end{abstract}

Keywords:

ABSTRACT. The Influence of the Catalyst Amount of $\mathrm{CaO}$ on the Product Characteristics in Glycerol Carbonate Synthesis. Glycerol carbonate is a glycerol derivative that is currently still developing its use. The synthesis of glycerol carbonate using glycerol and urea promises to be applied because raw materials are easier to obtain, handling is simpler and cheaper than other synthesis processes. This study aims to characterize the product of the urea glycerolysis reaction in the operating conditions of $140{ }^{\circ} \mathrm{C}$, the pressure of $0,7 \mathrm{~atm}$ for 4 hours with variation in the amount of $\mathrm{CaO}$ catalyst $1,2,3,4$, and $5 \%$ mol. Characterization of the reaction products was analyzed by functional groups using the FTIR instrument and compound composition analysis using the GC-MS instrument. The product analysis concluded that the optimum condition was obtained from the reaction of urea glycerolsis with $5 \%$ mol catalyst resulting in a conversion of $23 \%$.

\section{PENDAHULUAN}

Gliserol karbonat merupakan bahan yang memiliki dua gugus fungsi, dimana keduanya menjadikan bahan ini dapat berperan sebagai pelarut berbagai bahan organik atau bahan anorganik (diaplikasikan pada industri kosmetik, cat, dan akumulator). Pelarut polar protik ini sangat diminati karena bersifat tidak beracun dan memiliki titik didih yang tinggi (Claude et al., 2000). Perkembangan penelitian dan produksi gliserol karbonat masih terus berlanjut untuk mendapatkan jenis katalis dan kondisi operasi yang optimum. Beberapa pilihan bahan baku untuk sintesis gliserol karbonat diantaranya fosgen, urea, karbon dioksida, alkil karbonat, dan dialkil karbonat. Salah satu reaksi yang saat ini diminati untuk dijalankan adalah reaksi gliserolisis urea karena menggunakan bahan baku yang harganya relatif lebih murah dan mudah didapatkan.

Akan tetapi terdapat tantangan saat melakukan reaksi gliserolisis urea dimana gas amonia yang terbentuk harus dikeluarkan dari sistem, hal ini bertujuan untuk mengurangi kemungkinan terbentuknya produk samping senyawa siklik yang mengandung nitrogen seperti (R)-4-Hydroxymethyloxazolidine-2one (Sukirno and Fitriyano, 2018). Ada dua cara menghilangkan gas amonia yaitu dengan mengalirkan gas nitrogen secara konstan dengan laju alir $20 \mathrm{~mL} / \mathrm{jam}$ atau dilakukan pembuangan menggunakan pompa vakum dengan tekanan 0,039 - 0,059 atm untuk mendapatkan hasil yang optimum (Claude et al., 2000).

Tantangan lain muncul dari metode analisis produk untuk memastikan gliserol karbonat sudah terbentuk dan memperlihatkan jumlah produk yang dihasilkan. Beberapa metode yang dapat digunakan untuk analisis gliserol karbonat diantaranya adalah menggunakan NMR (Nuclear Magnetic Resonance) dimana spektrum sampel akan dibandingkan dengan data literatur spektrum bahan (Chiappe and Rajamani, 2012). Metode lain adalah menggunakan $G C-M S$ dengan cara membandingkan spektrum $G C-M S$ antara sampel dan basis data 
internal pada perangkat lunak $G C-M S$ data analysis yang disediakan oleh Instrumen. Suhu aliran masuk $G C-M S$ harus cukup tinggi untuk memastikan semua sampel menguap sempurna, tapi tidak terlalu tinggi karenaakan menyebabkan dekomposisi termal. Sebaliknya jika suhu terlalu rendah menyebabkan bahan tidak menguap sempurna dan terjadi perluasan puncak kromatografi (Stashenko and Martínez, 2014).

Penentuan konversi gliserol dapat dilakukan dengan beberapa pilihan, yang pertama analisis menggunakan metode titrasi iodometri untuk menentukan jumlah gliserol bebas dan dilakukan perhitungan konversi. Cara berikutnya menggunakan FTIR membandingkan antara sampel dengan standar yang konsentrasi bervariasi. Cara lainnya adalah dengan $G C-M S$, dimana dilakukan pengukuran jumlah gliserol yang terbaca pada hasil reaksi dengan acuan basis data pada perangkat lunak alat tersebut (Adhitasari et al., 2017; Hammond et al., 2011).

Kondisi operasi reaksi gliserolisis urea didapatkan dari hasil tinjauan beberapa penelitian terdahulu, dimana suhu optimum berada pada rentang suhu $140-150{ }^{\circ} \mathrm{C}$, tekanan $0,039-0,059 \mathrm{~atm}$, waktu reaksi $4-5$ jam dan rasio katalis $2,7-8,6 \%$. Pemilihan metode analisis memperlihatkan keberhasilan sintesis gliserol karbonat melalui reaksi gliserolisis urea, metode titrasi iodometri atau asam basa hanya mampu menunjukkan jumlah gliserol yang terkonversi atau gas ammonia yang terbentuk. Untuk melakukan konfirmasi secara kualitatif dan kuantitatif produk hasil reaksi harus diuji menggunakan metode $N M R$ atau $G C-M S$, serta datanya dibandingkan dengan data analisis dari sampel gliserol karbonat standar (Fitriyano et al., 2019).

Sintesis gliserol karbonat melalui reaksi gliserolisis urea pada beberapa penelitian sebelumnya telah dilakukan dengan berbagai jenis katalis, salah satu diantaranya adalah MCM-41 atau Mobil Composition of Matter No. 41 yang memiliki nilai konversi $84 \%$ dan yield $82 \%$ ketika dioperasikan pada suhu $140{ }^{\circ} \mathrm{C}$ selama 5 jam pada tekanan $1 \mathrm{~atm}$ dengan aliran gas nitrogen untuk mendorong keluar ammonia terbentuk dari reaktor selama reaksi berlangsung (Kondawar et al., 2017). Katalis lainnya adalah $\mathrm{MnSO}_{4}$ terkalsinasi yang dioperasikan pada suhu $150{ }^{\circ} \mathrm{C}$ selama 6 jam pada tekanan vakum $0,039 \mathrm{~atm}$ menghasilkan nilai yield $73 \%$. Katalis $\mathrm{ZnSO}_{4}$ terkalsinasi terbukti menghasilkan yield $80 \%$ telah dioperasikan pada suhu $150{ }^{\circ} \mathrm{C}$ selama 2 jam pada tekanan vakum 0,039 atm (Claude et al., 2000).

Pada sintesis gliserol karbonat melalui reaksi transesterifikasi dengan bahan baku gliserol dan dimetil karbonat menggunakan katalis $\mathrm{CaO}$ menghasilkan konversi optimum sebesar 96\%. Kondisi tersebut dicapai menggunakan katalis $\mathrm{CaO}$ sebesar $8 \%$ mol, dimana pada reaksi tersebut kondisi basa dijaga agar dapat meningkatkan jumlah konversi (Praikaew et al., 2018). Penggunaan katalis $\mathrm{CaO}$ juga terbukti pada penelitian lainnya dengan nilai konversi $94 \%$ melalui reaksi transesterifikasi menggunakan bahan baku gliserol dan dimetil karbonat dengan jumlah katalis sebesar 3\% mol CaO yang mengandung $\mathrm{LiCl} 10 \%$ (Teng et al., 2014). Pada penelitian ini dilakukan pencarian data baru terkait dampak jumlah katalis $\mathrm{CaO}$ terhadap karakteristik produk gliserol karbonat. Studi ini menerapkan kondisi operasi suhu $140{ }^{\circ} \mathrm{C}$, tekanan 0,7 atm selama 4 jam dengan variasi jumlah katalis $\mathrm{CaO} 1,2,3,4$, dan 5\% mol terhadap mol gliserol.

\section{METODE PENELITIAN}

Bahan-bahan yang digunakan pada penelitian ini diantaranya gliserol (kemurnian 90\%, tanpa merek), urea (teknis), $\mathrm{CaO}$ (teknis), gliserol karbonat (kemurnian > 96\%, merek TCI). Peralatan yang digunakan pada penelitian ini diantaranya plat pemanas dengan pengaduk magnet (merek IKA ${ }^{\circledR}$ C-MAG HS7), labu leher tiga Pyrex $250 \mathrm{cc}$, labu erlenmeyer, termometer $250^{\circ} \mathrm{C}$, tutup labu dari karet, kondensor, pompa vakum, statif, klem, FTIR Agilent Cary 630, dan GC-MSAgilent 5973 (kondisi operasi : gas pembawa Helium $1 \mathrm{~mL} / \mathrm{menit}$, rasio split $50: 1$, suhu awal $50{ }^{\circ} \mathrm{C}$, penigkatan suhu $20^{\circ} \mathrm{C}$ /menit, suhu akhir $280{ }^{\circ} \mathrm{C}$, waktu retensi 35 menit).

\section{Proses Sintesis dan Pemisahan Produk}

Sintesis gliserol karbonat melalui reaksi gliserolisis dengan memvariasikan jumlah katalis $\mathrm{CaO} 1,2,3,4$, $5 \%$ mol terhadap mol gliserol menggunakan bahan baku gliserol $51 \mathrm{~g}$ dan urea $30 \mathrm{~g}$. Reaksi tersebut dilakukan pada suhu $140{ }^{\circ} \mathrm{C}$, tekanan 0,7 atm selama 4 jam dengan kecepatan pengadukan level 4 pada alat IKA ${ }^{\circledR} \mathrm{C}-\mathrm{MAG}$ HS7. Proses pemisahan dilakukan menggunakan kertas saring Whatman No. 93 dan corong kaca dengan wadah labu erlenmeyer. Pemisahan dilakukan selama 15 jam dimana dihasilkan padatan katalis $\mathrm{CaO}$ pada kertas saring dan filtrat pada labu kaca. Setelah dilakukan proses sintesis dan pemisahan bahan hasil reaksi, produk yang dihasilkan selanjutnya dikarakterisasi. Metode analisis yang dilakukan terhadap produk diantaranya pengukuran densitas (Piknometer), gugus fungsi (FTIR), komposisi bahan (GCMS - ChemStation E.02.02.1431).

Untuk mendapatkan persen komposisi campuran, pertama-tama tambahkan semua area puncak. Kemudian, untuk menghitung persentase senyawa apapun dalam campuran, selanjutnya membagi area individualnya dengan 
area total dan mengalikan hasilnya dengan 100. Metode ini sangat berguna karena memberikan hasil yang cukup akurat (Wahl and Gallardo-Williams, 2011). Konversi bahan pada reaksi setara dengan jumlah mol bahan yang bereaksi dibandingkan dengan jumlah mol bahan yang sama pada saat awal reaksi. Dalam penelitian ini gliserol sebagai basis konversi dihitung menggunakan persamaan 1 .

$$
\text { Konversi }=\frac{\text { mol gliserol awal }- \text { mol gliserol sisa }}{\text { mol gliserol awal }}
$$

\section{HASIL PEMBAHASAN}

Reaksi antara gliserol dengan urea pada sintesis gliserol karbonat dapat dilihat pada Gambar 1. (Kondawar et al., 2017).

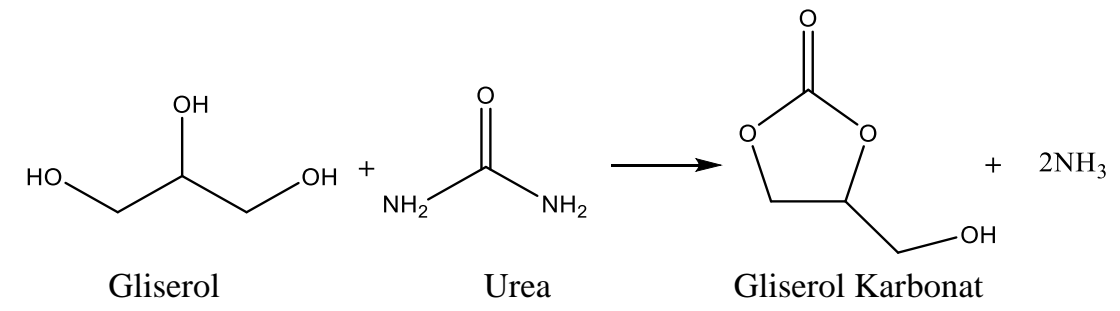

Gambar 1. Reaksi gliserolisis urea.

Bahan hasil reaksi dipisahkan dari katalis dengan cara penyaringan di suhu ruangan. Densitas bahan dari hasil reaksi gliserolisis urea dengan variasi katalis seperti ditampilkan pada Tabel 1. Berdasarkan referensi diketahui densitas gliserol adalah 1,261 $\mathrm{g} / \mathrm{mL}$, urea memiliki densitas sebesar 1,32 $\mathrm{g} / \mathrm{mL}$ (padat), 1,11 g/mL (larutan urea 40\%), 1,175 g/mL (larutan urea 70\%), dan densitas gliserol karbonat komersil yaitu 1,4 g/mL. Jika dibandingkan dengan data tersebut, dari Tabel 1 dapat dilihat bahwa hasil reaksi dengan katalis $2 \%$ mol merupakan bahan yang densitasnya paling mendekati gliserol karbonat yaitu dengan nilai $1,38 \mathrm{~g} / \mathrm{mL}(\mathrm{CF}$ Industries, 2015; Rossi and Pagliaro, 2008; TCI, 2018).

Tabel 1. Densitas bahan hasil reaksi.

\begin{tabular}{cc}
\hline Jumlah Katalis $(\% \mathbf{~ m o l})$ & Densitas $(\mathbf{g} / \mathbf{m L})$ \\
\hline 1 & 1,3052 \\
2 & 1,3872 \\
3 & 1,2633 \\
4 & 1,3124 \\
5 & 1,3522 \\
\hline
\end{tabular}

Densitas bahan hasil reaksi lebih rendah dibandingkan dengan densitas gliserol karbonat komersil hal ini dimungkinkan karena adanya gliserol yang belum terkonversi. Untuk memperlihatkan adanya gliserol yang terkonversi menjadi produk yang diinginkan yaitu gliserol karbonat maka dilakukan analisis terhadap gugus fungsi menggunakan instrumen FTIR. Gambar 2 merupakan spektra infra merahdari gliserol karbonat standar, gliserol standar serta bahan hasil reaksi gliserolisis urea. Spektrum FTIR dari gliserol karbonat standar komersil terlihat adanya gugus fungsi $\mathrm{C}=\mathrm{O}$ pada bilangan gelombang $1759 \mathrm{~cm}^{-1}$ dengan area yang besar, selain itu juga ada gugus fungsi C-O-C pada bilangan gelombang 1078 dan $1106 \mathrm{~cm}^{-1}$ (Merck, 2019). Hasil analisis produk reaksi menggunakan spektrum FTIR menunjukkan bahwa pada penggunaan katalis 1 dan $2 \%$ mol memperlihatkan adanya pembentukan gugus karbonat akan tetapi areanya masih sedikit.

Area yang memperlihatkan terbentuknya gugus $\mathrm{C}=\mathrm{O}$ lebih besar terlihat pada spektrum FTIR dengan bilangan gelombang 1720 hingga $1760 \mathrm{~cm}^{-1}$ pada penggunaan katalis 3, 4, dan $5 \%$ mol. Untuk area pada spektrum lainnya masih memperlihatkan kemiripan dengan spektrum FTIR milik gliserol komersil di Gambar 3. Sehingga dapat diketahui bahwa sudah ada gliserol yang terkonversi membentuk senyawa dengan gugus karbonat dan masih terdapat sejumlah gliserol yang belum terkonvesi pada produk. Berdasarkan data densitas produk dan analisis FTIR, maka hasil reaksi yang dipilih untuk uji $G C-M S$ adalah produk dengan penggunaan $2 \%$ mol dan $5 \%$ mol katalis CaO. Berdasarkan analisis GC-MS didapatkan tampilan spektra komposisi senyawa dari hasil reaksiyang dapat dilihat pada Gambar 3. 


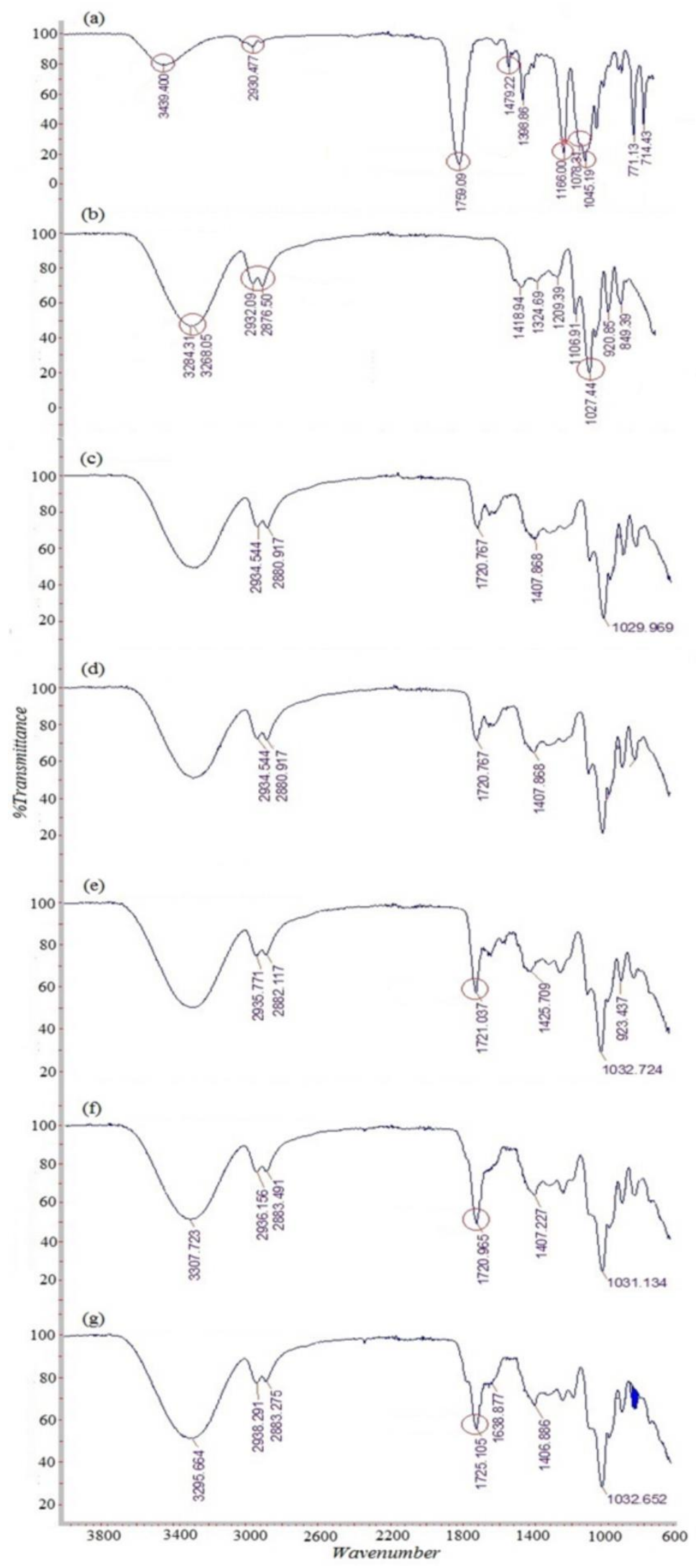

Gambar 2. Spektra FTIR (a) gliserol karbonat kemurnian > 96\% merek TCI, (b) gliserol kemurnian 90\% dan $(\mathrm{c}-\mathrm{g})$ hasil reaksi dengan variasi katalis 1 hingga $5 \%$ mol.

Pada analisis bahan hasil reaksi dengan instrument $G C-M S$, tersedia data internal pada perangkat lunak $G C$ MS data analysis yang mampu memberikan informasi waktu retensi, rumus kimia, dan kualitas. Dari 
kromatogram $G C$ dapat dilihat terbentuknya senyawa Glycidol pada produk hasil reaksi yaitu pada tR 10.693 dan gas karbon dioksida pada tR1.354. Jumlah gliserol masih terlihat cukup banyak di kedua sampel produk, hal ini diperlihatkan pada area yang besar dengan rentang $t R$ antara 7.00 hingga 10.00. Serta terlihat pembentukan senyawa siklik 1,3-Dioxol-2-one pada rentang tR 14.00 hingga 16.00 .

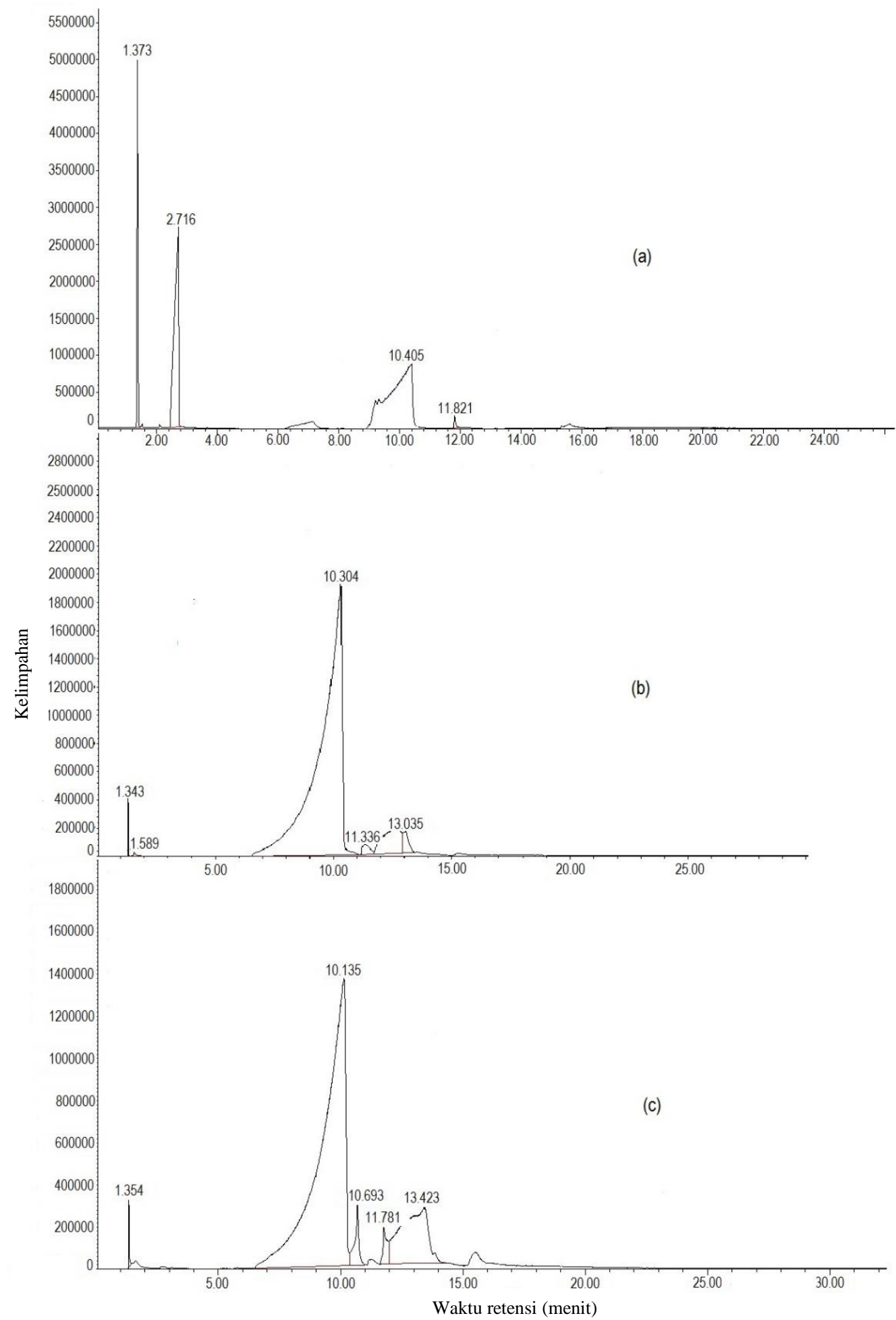

Gambar 3. Kromatogram $G C$ (a) gliserol karbonat kemurnian > 96\% merek TCI, (b) hasil reaksi dengan katalis $2 \%$ mol dan (c) $5 \%$ mol.

Dampak dari penggunaan pompa vakum selama reaksi menghasilkan produk yang sudah tidak mengandung gas amonia terlarut, akan tetapi masih terbentuk senyawa siklik yang mengikat nitrogen terlihat pada senyawa $N$ Ethylrhodanine. Hal tersebut dapat disebabkan oleh kemampuan pompa vakum yang digunakan berada pada 
tekanan 0,7 atm, dimana berdasarkan referensi seharusnya rentang tekanan berada diantara 0,039-0,059 atm (Oprescu et al., 2012). Pada penelitian lainnya pembuangan ammonia yang terbentuk selama reaksi berlangsung dilakukan dengan cara mengalirkan gas nitrogen sebagai gas inert (Chen et al., 2015). Berdasarkan buku literatur tentang kromatografi gas, diketahui bahwa area di bawah puncak kromatografi gas sebanding dengan jumlah (mol) senyawa yang dielusi. Oleh karena itu, komposisi persentase molar suatu campuran dapat diperkirakan dengan membandingkan area puncak relatif. Metode analisis ini mengasumsikan bahwa detektor sama sensitifnya terhadap semua senyawa yang dielusi dan memberikan respon linier berkaitan dengan jumlah senyawa.

Tabel 2. Komposisi senyawa gliserol karbonat kemurnian > 96\% merek TCI, hasil reaksi dengan katalis $2 \%$ mol dan $5 \%$ mol.

\begin{tabular}{|c|c|c|c|}
\hline Nama Komponen & $\begin{array}{c}\text { Gliserol Karbonat } \\
\text { Kemurnian }>96 \% \text { merek } \\
\text { TCI } \\
(\% \mathrm{~mol})\end{array}$ & $\begin{array}{c}2 \% \text { mol Katalis } \mathrm{CaO} \\
(\% \mathrm{~mol})\end{array}$ & $\begin{array}{c}5 \% \text { mol Katalis } \mathrm{CaO} \\
(\% \mathrm{~mol})\end{array}$ \\
\hline Carbon dioxide & 13,74 & 0,37 & 0,4 \\
\hline Glycerol & - & 90,12 & 77,24 \\
\hline Glycidol & 86,26 & - & 2,86 \\
\hline$N$-Ethylrhodanine & - & - & 1,73 \\
\hline 1,3-Dioxol-2-one & - & 9,51 & 17,76 \\
\hline
\end{tabular}

Pada penggunaan katalis $\mathrm{CaO} 2 \%$ mol, nilai konversi hanya sekitar 9,88\% dan pada produk sudah mulai terlihat adanya pembentukan gugus siklik yang dibuktikan dengan adanya senyawa 1,3-Dioxol-2-one sebanyak 9,51\%. Pada penggunaan katalis $\mathrm{CaO} 5 \%$ mol, nilai konversi meningkat menjadi $23 \%$ dan pada produk sudah mulai terlihat peningkatan pembentukan gugus siklik yang dibuktikan dengan adanya senyawa 1,3-Dioxol-2-one sebanyak $17,76 \%$ dan $N$-Ethylrhodanine $1,73 \%$. Selain itu juga terdapat senyawa Glycidol sebanyak 2,86\%, dimana senyawa ini merupakan hasil reaksi pemecahan gliserol karbonat dengan hasil samping karbon dioksida.

Instrumen analisis $G C-M S$ masih belum mampu menampilkan struktur produk utama yang diinginkan yaitu gliserol karbonat, akan tetapi dengan terbentuknya senyawa 1,3-Dioxol-2-one dan N-Ethylrhodanine menunjukkan bahwa reaksi sudah mengkonversi gliserol ke dalam bentuk senyawa siklik yang memiliki gugus fungsi karbonat. Penggunaan instrumen $G C-M S$ untuk analisis gliserol karbonat kurang tepat karena jika dioperasikan pada suhu rendah menyebabkan tekanan uap tidak tercapai dan tidak terbentuk uapnya. Sedangkan jika dioperasikan pada suhu tinggi gliserol karbonat yang menguap akan mengalami dekomposisi termal dan menghasilkan senyawa glysidol dan karbondioksida.

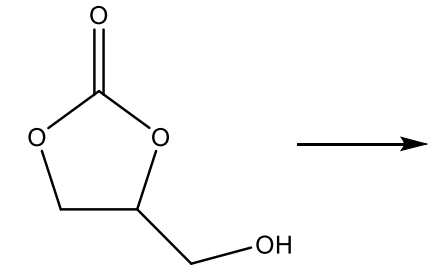

Gliserol karbonat

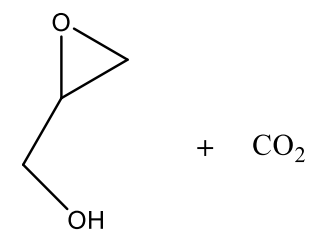

Glysidol

Gambar 4. Reaksi pembentukan glisidol (Bartoli et al., 2018).

Hal ini dibuktikan dengan hasil uji GC-MS senyawa gliserol karbonat standar TCI yang menampilkan hasil analisis yaitu kedua senyawa tersebut. Pada beberapa penelitian digunakan NMR dengan sampel standar sehingga didapatkan perbandingan antara spektra bahan hasil reaksi dengan spektra bahan standar dan data literatur bahan. Tentu saja hal ini memugkinkan untuk dilakukan, akan tetapi ada beberapa kendala yang harus dipertimbangkan jika ingin menggunakan instrumen tersebut. Prosedur uji yang tidak tersedia khusus untuk gliserol karbonat sehingga masih harus dilakukan uji coba metode analisis dan biaya analisis yang cukup tinggi untuk setiap sampelnya.

\section{KESIMPULAN}

Sintesis gliserol karbonat melalui reaksi gliserolisis urea dengan penggunaan katalis $\mathrm{CaO} 5 \%$ mol memiliki nilai konversi $23 \%$ dan karakteristik produk lebih optimum pada penelitian ini dibandingkan produk lainnya. Hal 
ini didukung oleh hasil pengujian karakteristik produk yang diantaranya densitas, analisis gugus fungsi, dan analisis komposisi senyawa hasil reaksi.

\section{UCAPAN TERIMA KASIH}

Peneliti mengucapkan terima kasih kepada Pusat Afiliasi Kajian dan Riset Teknologi Fakultas Teknik Universitas Muhammadiyah Jakarta (PAKARTI FT UMJ) atas dukungannya dalam pendanaan penelitian ini dengan nomor surat perjanjian 360/F.4-UMJ/IX/2019.

\section{DAFTAR PUSTAKA}

Adhitasari, A., Sulistyo, H., and Prasetya, A., 2017. Sintesis Gliserol Karbonat dari Gliserol dan Urea Menggunakan Katalis Resin Indion 225 Na. Reaktor 17(3), 139-143.doi: 10.14710/reaktor.17.3.140-144.

Bartoli, M., Zhu, C., Chae, M., and Bressler, D.C., 2018. Value-Added Products from Urea Glycerolysis Using a Heterogeneous Biosolids-Based Catalyst. Catalysts 8(9), 373.doi: 10.3390/catal8090373.

Urea Liquor Safety Data Sheet, 2015.CF Industries. Illinois.

Chen, J., Wang, C., Dong, B., Leng, W., Huang, J., Ge, R., and Gao, Y., 2015. Ionic Liquids as Eco-Friendly Catalysts for Converting Glycerol and Urea into High Value-Added Glycerol Carbonate. Chinese Journal of Catalysis36(3), 336-343. doi: 10.1016/S1872-2067(14)60257-6.

Chiappe, C. and Rajamani, S., 2012. Synthesis of Glycerol Carbonate from Glycerol and Dimethyl Carbonate in Basic Ionic Liquids. Pure and Applied Chemistry 86(3), 755-762. doi: 10.1351/PAC-CON-11-07-06.

Claude, S., Mouloungui, Z., Yoo, J.-W., and Gaset, A.,2000. U.S. Patent No. 6,025,504. United States Patent, Washington DC.

Fitriyano, G., Sukirno, S., and Fauziah, S. 2019. Tinjauan Unjuk Kerja Sintesis Gliserol Karbonat Melalui Reaksi Karbonilasi Gliserol dengan Urea. In: FT UMJ (Ed.), Prosiding Seminar Nasional Sains dan Teknologi 2019. Semnastek, 16 Oktober 2019, Jakarta. FT UMJ, Jakarta, pp. 1-8.

Hammond, C., Lopez-Sanchez, J.A., Rahim, M.H.A., Dimitratos, N., Jenkins, R.L., Carley, A.F., He, Q., Kiely, C.J., Knight, D.W., and Hutchings, G.J., 2011. Synthesis of Glycerol Carbonate from Glycerol and Urea with Gold-Based Catalysts. DaltonTransactions 40(15), 3927-3937. doi: 10.1039/C0DT01389G.

Kondawar, S.E., Mane, R.B., Vasishta,A., More, S.B., Dhengale, S.D., and Rode, C.V., 2017. Carbonylation of Glycerol with Urea to Glycerol Carbonate Over Supported Zn Catalysts. Applied Petrochemical Research7, 41-53. doi: 10.1007/s13203-017-0177-2.

Merck., 2019. IR Spectrum Table and Chart. <https://www.sigmaaldrich.com/technicaldocuments/articles/biology/ir-spectrum-table.html> (diakses pada12 Desember 2019).

Oprescu, E.-E., Stepan, E., Rosca, P.A.U.L., Radu, A., and Enascutã, C.-E., 2012. Synthesis of Glycerol Carbonate over Hydrotalcite Catalyst. Revista de Chimie 63(6), 621-625.

Praikaew, W., Kiatkittipong, W., Kiatkittipong, K., Laosiripojana, N., Viriya-empikul, N., Boonyasuwat, S., Aiouache, F., Najdanovic, V., and Assabumrungrat, S., 2018. The Synthesis of Glycerol Carbonate from Dimethyl Carbonate and Glycerol Using Cao Derived from Eggshells. In: MATEC Web of Conferences. ICEAST 2018, 4-7 Juli 2018, Phuket, Thailand. EDP Sciences, Les Ulis, France, pp. 1-4. doi: $10.1051 /$ matecconf/201819203045.

Rossi, M. and Pagliaro M., 2008. The Future of Glycerol, second ed. Royal Society of Chemistry Publishing, Washington DC (Chapter 1). doi: 10.1039/9781849731089.

Stashenko, E. and Martínez, J. R., 2014. Advances in Gas Chromatography. IntechOpen, London (Chapter 1). doi: $10.5772 / 57492$.

Sukirno, S. and Fitriyano, G., 2018. Carbonylation Reaction between Glycerol and Urea using CaO Catalyst. Jurnal Kimia Sains Dan Aplikasi 21(4), 211-217. doi: 10.14710/jksa.21.4.211-217.

Glycerol 1,2-Carbonate Safety Data Sheet, 2018. TCI. Tokyo.

Teng, W.K., Ngoh, G.C., Yusoff, R., and Aroua, M.K., 2014. A Review on the Performance of Glycerol Carbonate Production via Catalytic Transesterification: Effects of Influencing Parameters. Energy Conversion and Management 88, 484-497. doi: 10.1016/j.enconman.2014.08.036.

Wahl, G. and Gallardo-Williams, M., 2011. Dehydration of Alcohols-Gas Chromatography. In: Microscale Experiments in Organic Chemistry 1 lst edition Custom Labs.<https://webassign.net/sample/ncsumeorgchem1/lab_4/manual.html> 